\title{
INVESTIGATING OF ECO- AND ENERGY-EFFICIENT LUBRICATION STRATEGIES FOR THE DRILLING OF LIGHT METAL ALLOYS
}

\author{
N.F. Treurnicht ${ }^{1 *}$, H.J . J oubert ${ }^{2}$, G.A. Oosthuizen ${ }^{3}$ and G. Akdogan ${ }^{4}$ \\ 1,2,3,4 Department of Industrial Engineering \\ University of Stellenbosch, South Africa \\ nicotr@sun.ac.za, h2j@sun.ac.za, tiaan@sun.ac.za, gakdogan@sun.ac.za
}

\begin{abstract}
Energy use will be one of the main drivers for the achievement of more eco-efficient drilling processes in the automotive industry. Industry awareness of the environmental impact of used cutting emulsions, and the negative effect on worker health, has increased sharply. This has led to innovative lubrication methods such as through-spindle minimal quantity lubrication (MQL) for drilling aluminium-silicon alloys. In this work the performance of MQL at different cutting speeds and feed rates has been investigated using infrared temperature measurements. The results indicate that MQL is a feasible ecoefficient alternative to conventional flood cooling when drilling aluminium-silicon alloys.
\end{abstract}

\section{OPSOMMING}

Energiebenutting maak een van die hoofdryfvere uit om eko-doeltreffendheid te behaal in boorprosesse in die motornywerheid. Nywerheidsbewustheid van die omgewingsimpak van gebruikte sny-vloeistowwe, en die negatiewe effek daarvan op werkergesondheid, het skerp toegeneem. Hierdie bewustheid het aanleiding gegee tot die ontwikkeling van smeringsmetodes soos deur-spil minimale hoeveelheid smering (Engels: Minimal Quantity Lubrication, MQL) vir die boor van aluminium-silikon legerings. In hierdie werk word die prestasie van MQL ondersoek teen verskillende snyspoed- en voertempo-kondisies deur middel van infra-rooi temperatuurmeting. Die resultate dui daarop dat MQL 'n lewensvatbare eko-vriendelike alternatief tot konvensionele vloedverkoeling is, wanneer aluminium-silikon legerings geboor word.

\footnotetext{
${ }^{1}$ The author was enrolled for an PhD (Industrial) degree in the Department of Industrial Engineering, University of Stellenbosch.

2 The author was enrolled for an MSc Eng (Industrial) degree in the Department of Industrial Engineering, University of Stellenbosch.

3 The author was enrolled for an PhD (Industrial) degree in the Department of Industrial Engineering, University of Stellenbosch.

* Corresponding author.
} 


\section{INTRODUCTION:}

In the automotive industry, with design trends towards lower mass and higher energy efficiency engines, more stringent tolerances are required, which in turn challenge the machining operations. Increasingly the world will be assessing material removal rates with a primary focus on the machining power (kW) demanded [1]. In societies of the twentieth century and beyond, the strength of a country's manufacturing sector is either directly correlated with the present status of social development, or has a long history of contribution to a secondary economy such as international financial services. The prominence of manufacturing is further increasing as innovation cycles become shorter. To develop comprehensive technologies that enable the creation of novel product features in terms of efficiency and added value, the complete value chain within the production has to be considered [2]. Advanced manufacturing technologies can contribute to higher efficiency along the whole value creation chain, and increase the eco-efficiency of the manufactured products.

The manufacturing industry has always aimed for productivity increases and quality improvement in its operations. In order to achieve higher productivity, elevating cutting performance remains a key opportunity. The drivers of change in cutting technology are summarized in Figure 1. Byrne et al. [1] found that the key drivers include: reduction of component size, enhanced surface quality, tighter tolerances and manufacturing accuracies, minimising costs, reducing weight, and smaller batch sizes. These drivers towards change have a direct influence on the primary inputs of the cutting process of which the cooling and lubrication forms part.

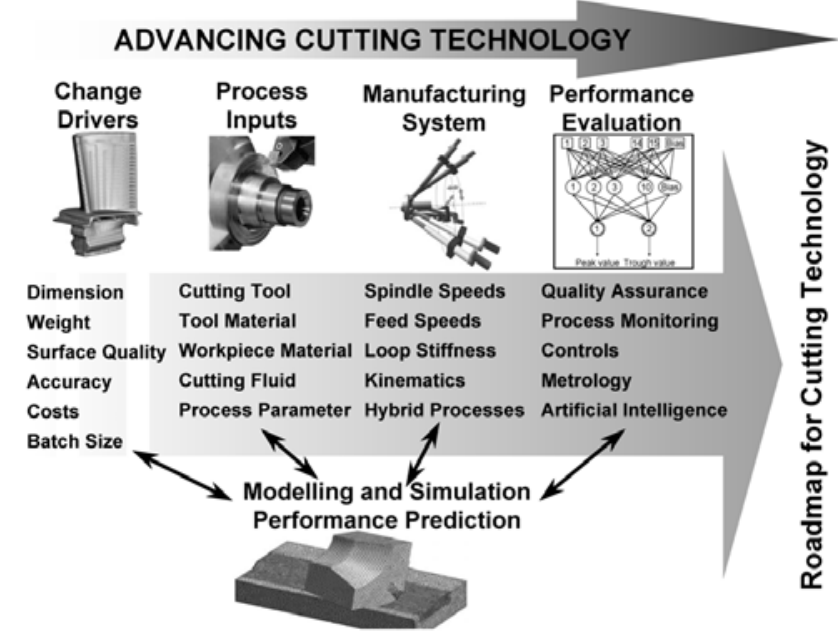

Figure 1: Primary aspects associated with advancing cutting technology [1]

The individual industrial branches drive the specific demands for new innovations using the different engineering materials. In the automotive sectors in particular, the use of lightweight energy-saving materials plays a vital role for structural components. Recent work on cutting edge engineering has shown that significant benefits can be obtained by very careful analysis of the precise mechanisms underlying material removal. One of the primary issues in high performance cutting is the material removal rate. Figure 2 illustrates the material removal rates for turning, milling, and drilling. 


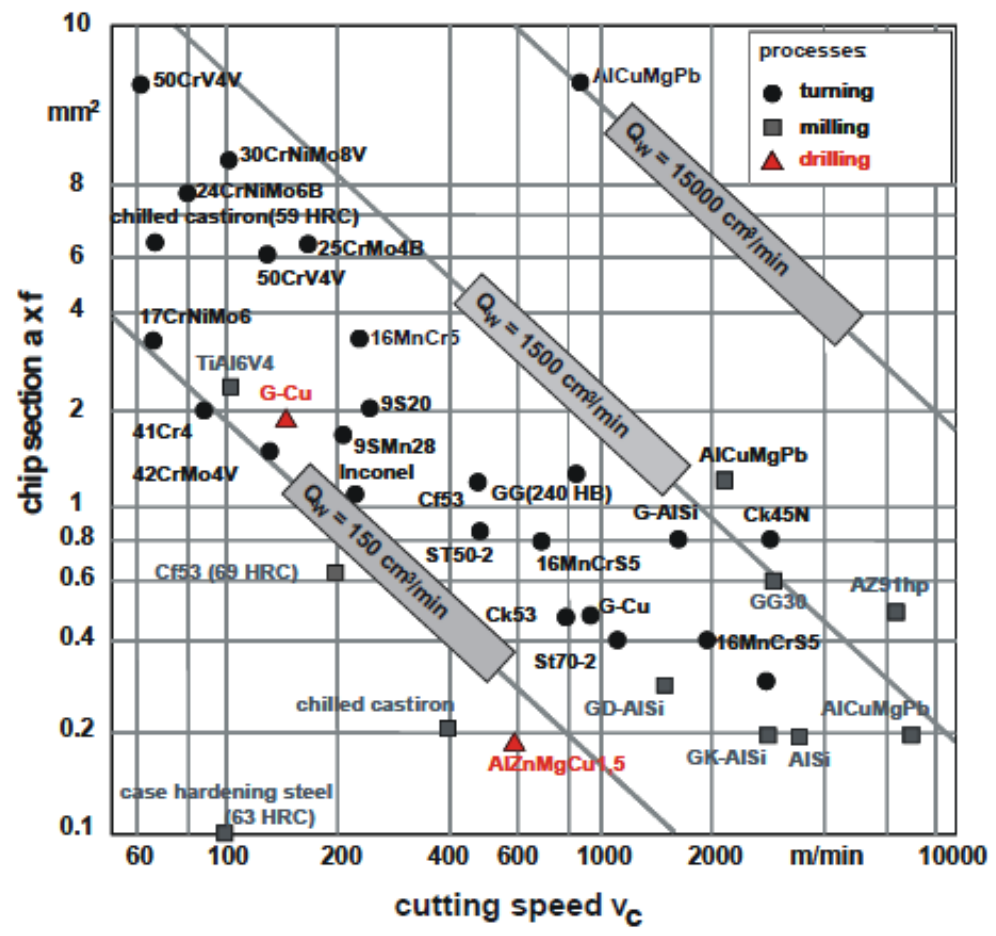

Figure 2: Material removal for a range of materials and cutting processes [1]

The material removal rate that is the main target for an optimised high performance cutting process is calculated by the chip section and the cutting speed. The competitive nature of the machining industry creates a constant demand for higher productivity. Improving these cutting parameters results in higher thermal and mechanical demands at the tool-chip interface [3]. The cutting edge is exposed to high temperatures and high cutting forces. The tool's outer corner in particular wears out quickly because of the high temperatures, since the possibility of effective cooling is extremely limited. By keeping the tool temperature low, its resistance to diffusion and abrasive wear is preserved. During drilling the lubricant plays an important role in the performance of the machining operations. This is due to the lubricant's friction-reducing, cooling, and chip removal properties [3]. In the past, flood cooling from an external nozzle was always the accepted way to lubricate high speed machining of aluminium-alloys. It has, however, become evident that the use of an abundant amount of lubricant could lead to a significantly adverse impact on the immediate environment, and present risks to the health of workers [4]. It has been proven that extended exposure to cutting fluids and their vapours could lead to skin and respiratory diseases [5]. Costs related to cutting fluids are also high, exceeding those related to labour and overhead expenses [6-9]. For these reasons alternative cooling methods, such as dry machining and minimal quantity lubrication, have been investigated. In the past dry drilling of aluminium-silicon alloys, especially where the hole depth exceeds the diameter, was considered impossible [10]. This is mainly due to the high ductility of aluminium-silicon alloys. During drilling operations where no cooling or lubrication is used, the chips will adhere to the tool and result in catastrophic tool failure [5]. During the machining process, most of the power that is consumed is converted into heat. Figure $3 a$ illustrates the energy flow during machining. The goal is to maximise the ratio of the net value added energy over the energy input. 

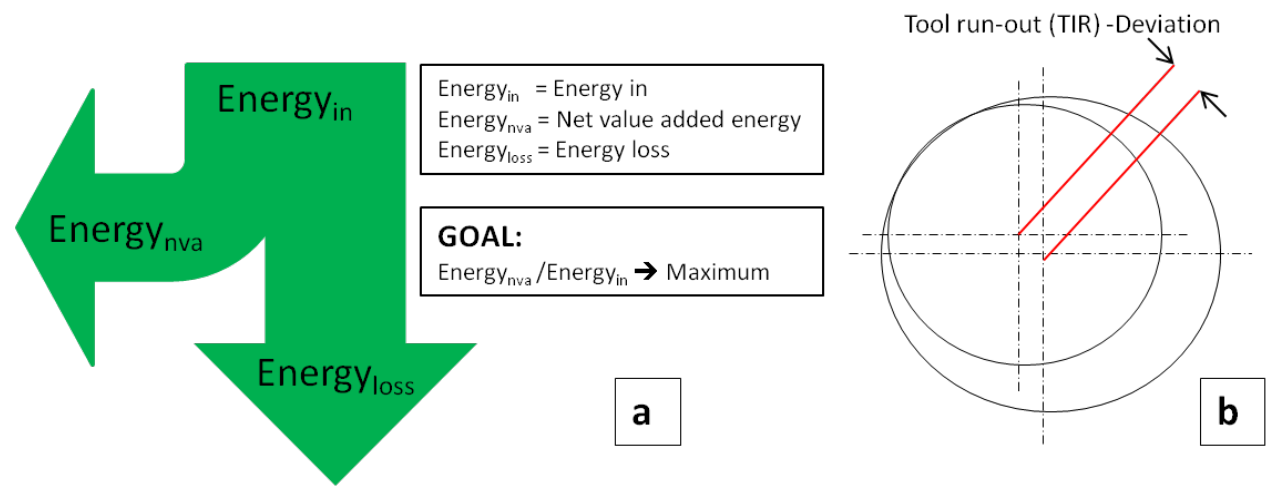

Figure 3: (a) Energy flow during machining [11] \& (b) Tool run-out due to vibration and thermal expansion

The increase in the amount of heat generated will also increase the temperature of the cutting tool and the work piece at the tool-chip interface. Elevated temperatures also induce adverse effects such as thermal expansion and tool wear, resulting in a loss of dimensional tolerance [12]. Figure $3 b$ illustrates tool run-out that leads to hole-diameter deviation through vibration and thermal expansion. The higher cutting temperatures promote thermally-related tool wear - for example, diffusion and adhesion [13]. The surface integrity is impaired due to the tensile residual stresses induced by the tool wear, causing surface and subsurface micro-cracks in addition to rapid corrosion and oxidation $[14,15]$. Therefore, tool wear causes deterioration of the surface integrity of the work piece and increased cutting forces and chatter vibration [12], the combined effect of which is a drilling process that consumes more energy. To a large extent, the effectiveness of the lubrication during machining operations determines the tool life [16]. Adhesion, attrition, and diffusion are the main mechanisms of tool wear at elevated cutting speeds $[5,16]$. This increase in temperature can be put down to the deformation associated with large shear strains in the primary shear zone, and the effects of friction along the tool-chip interface [17]. These wear mechanisms cause the formation of crater wear on the wear land that, in this case, is situated inside the drill spiral, close to the cutting edge. This is referred to as the 'tool rake face' in generic machining terms [18]. So this study aimed to compare the minimal quantity lubrication strategies with flood lubrication when drilling an automotive aluminium-silicon in different conditions. The goal was to find an energy efficient alternative that drills dimensionally accurate holes and reduces noxious substances - in this case, oil-water emulsion cutting fluids and gases - that have to be disposed of, or are simply released into the environment.

\section{EXPERIMENTAL SET-UP}

The experiments were designed to simulate horizontal drilling in aluminium wheel manufacturing. The lubricant-air mixture was fed through a connecting tube from the MQL system to the back of the drill bit that simulated through spindle lubrication in a horizontal CNC drilling machine. Figure 4 illustrates the experimental set-up. The lubricant used was oil specifically formulated for MQL applications. The MQL tests were conducted using only oil and an oil-water mixture. The oil-water mixture had a ratio of 15 parts oil to 4 parts water. The MQL applicator was set to deliver $25 \mathrm{ml}$ of lubricant/coolant per hour. 


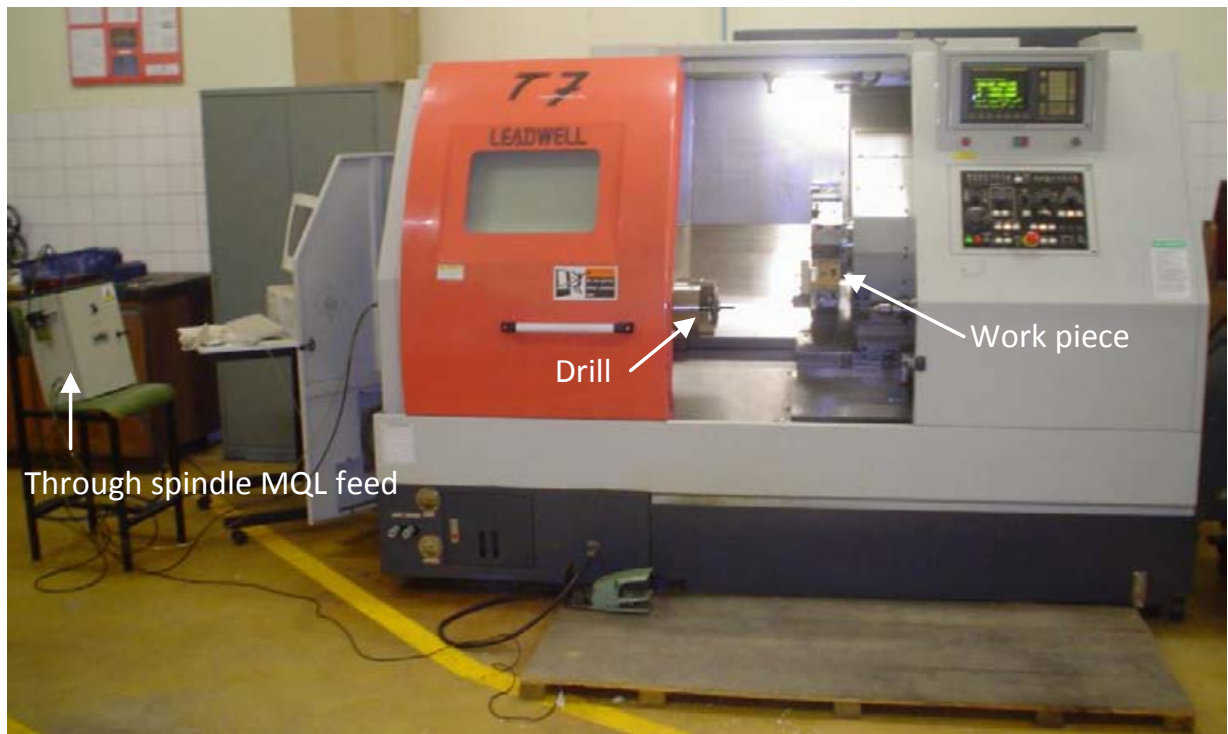

Figure 4: Experiment to simulate horizontal drilling

The lubricant-air mixture was supplied at a pressure of 6 bars. The tests were conducted on a Leadwell T7 CNC lathe. Two different drills were tested during the experiments, as illustrated in Figure $5 \mathrm{a}$ and Figure $5 \mathrm{~b}$. The first drill was an indexable step and chamfer (ISC) drill, and the second drill was a high feed indexable insert (HFII) drill. The positioning of the inserts for the HFII-drill is equivalent to only one cutting edge for each rotation of the drill. The result is that the material removal rate is half of that of a normal drill with two cutting edges per revolution.
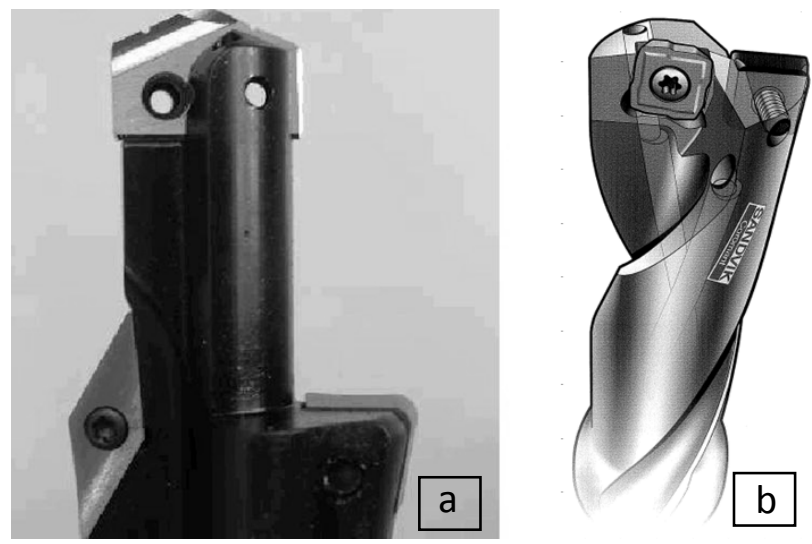

Figure 5: (a)The indexable step and chamfer drill and (b) the high feed indexable insert drill [19]

The manufacturers of the HFII-drill also claim that the special bevel design of the inserts causes the tool to vibrate slightly, assisting in chip breakage. An increase in chip breaking capability would lead to a shorter contact length of the chips with the tool. This reduced contact length leads to the generation of less heat, hence less diffusion and tool wear. The machining conditions and tool dimensions are shown in Table 1. 


\begin{tabular}{|l|ll|}
\hline Cutting speed $\left(\mathrm{V}_{\mathrm{c}}\right)$ & $94.2-240 \mathrm{~m} / \mathrm{min}$ & \\
\hline Feed $\left(\mathrm{f}_{\mathrm{n}}\right)$ & $0.067-0.15 \mathrm{~mm} /$ rev & $: 27 \mathrm{~mm}$ \\
\hline Drilling depth $\left(\mathrm{I}_{4}\right)$ & Indexable step and chamfer & $: 24 \mathrm{~mm}$ \\
& Indexable insert drill & $: 17 \mathrm{~mm}$ \\
& Indexable step and chamfer & $: 15 \mathrm{~mm}$ \\
\hline
\end{tabular}

\section{Table 1: Drilling conditions and parameters}

All the tests were conducted on aluminium-alloy samples that contain $9-12 \%$ silicon. The samples $(300 \times 50 \times 23 \mathrm{~mm})$ were clamped as shown in Figure 6 . Different cutting speeds and feed rates were used with the different tools and lubrication methods. To ensure that horizontal industrial drilling processes were simulated realistically, the work piece was held stationary, while the drill bit was rotated.

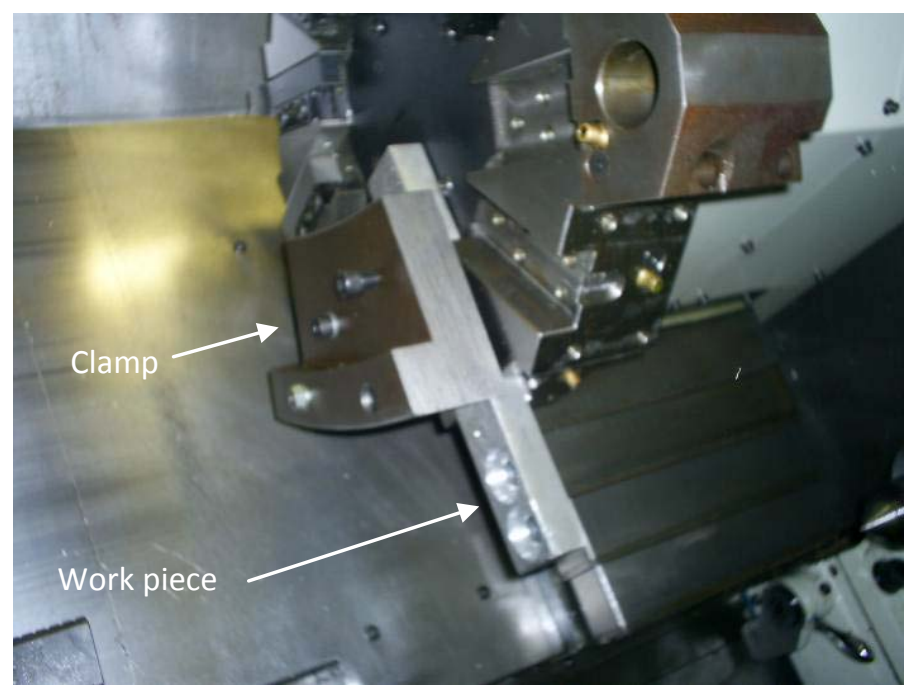

Figure 6: The clamping configuration used to keep the work piece in position

Different aspects of the hole that was drilled were considered when the results were compared. The primary cutting parameter optimisation criteria were the post-drilling temperature of the drill bit and the quality of the hole, quantified by its dimensional accuracy. The same experiments were conducted for both of the drills. Results for the different cutting configurations were compared for each drill. The cutting configurations for one drill were compared with similar cutting configurations for the other drill. The postdrilling temperatures that were generated were captured using infrared photography. The camera has an infrared display screen at the back that assists the photographer in focusing the camera in the right direction. All the data that are captured on the camera are then loaded on to a computer. For each photograph taken, the camera supplies a grid containing $160 \times 120$ different temperatures. The maximum temperature for each photograph is also indicated. Figure 7 gives an indication of a typical infrared photograph when it is uploaded to a computer. 


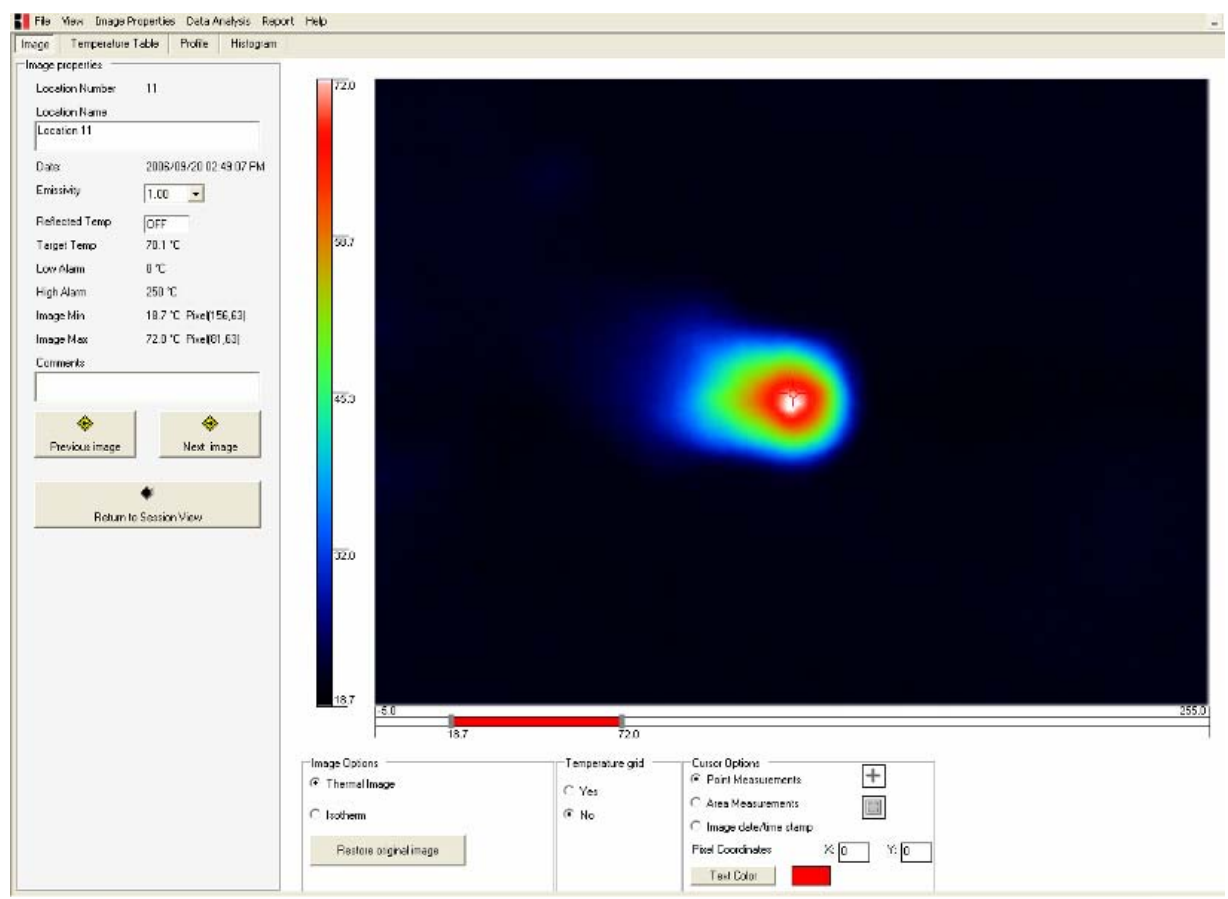

Figure 7: A typical infrared photograph taken of the drill

The dimensional accuracy was compared by measuring the deviation of the hole from the drill diameter. The smaller the deviation, the more accurate were the holes. This could result in a better quality hole and less friction during the drilling operation, leading to better energy consumption. To ensure that the hole diameters were accurately measured, a telescopic gauge and micrometer with one micron accuracy were used.

\section{RESULTS}

The experiments were conducted, and the results were captured through the use of infrared photography. The drills could be compared to determine which was best suited for the machining of aluminium-alloys with MQL methods. Figure 8 illustrates the temperatures that were captured for the ISC-drill plotted as a function of feed and cutting speed.

The graph shows that there was an upward trend in the post-drilling temperatures as feed and cutting speed increased. For different cutting conditions, where the feed was held constant while the cutting speed was increased, the post-drilling temperature rose. The same trend is visible, but less significantly, when the cutting speed was held constant and the feed was increased. The lowest temperatures were recorded at a cutting speed of 106.8 $\mathrm{m} / \mathrm{min}$ with a feed of $0.1 \mathrm{~mm} / \mathrm{rev}$. It is important to note that all the experiments - except the last - were conducted using only the MQL oil as lubricant. In the last experiments it was decided to add $21 \%$ water and to determine the effect on post-drilling temperatures. The machine was run at its maximum cutting speed of $240 \mathrm{~m} / \mathrm{min}$ and a feed of $0.15 \mathrm{~mm} / \mathrm{rev}$. The addition of water had a distinctly positive effect on reducing the amount of heat accumulated in the insert. In the literature a similarly positive effect on tool life was reported after adding water to the MQL lubricant/ coolant. The main mechanism causing the improvement is proved to be the chilling effect [4]. The temperature measurement went completely against the trend. Higher temperature values were expected at these cutting conditions than those measured before. Instead, there was a significant reduction in the post-drilling temperatures. This was put down to the increased thermal capacity of the water/oil mixture. Figure 9 illustrates the hole-deviation for the ISC-drill plotted as a function of feed and cutting speed. 


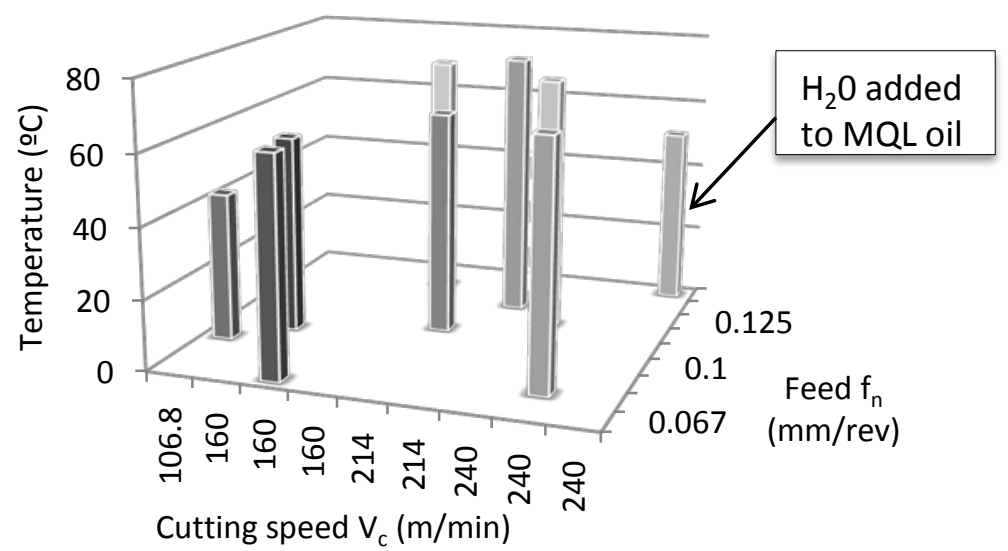

Figure 8: Temperature as a function of feed rate and cutting speed for the indexable step and chamfer drill

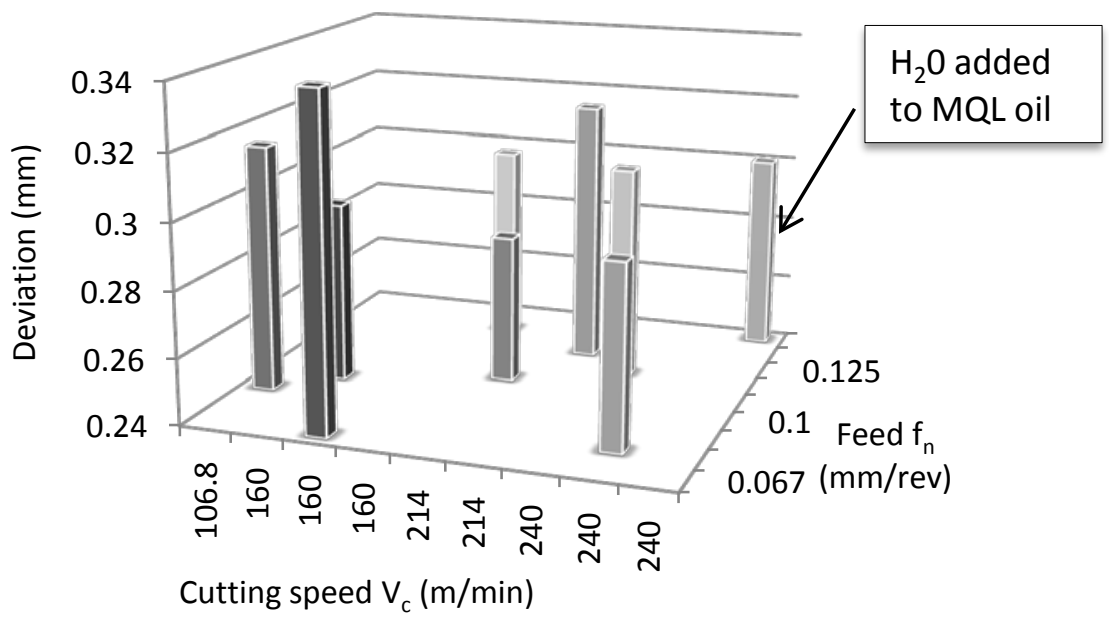

Figure 9: Hole deviations for the indexable step and chamfer drill experiments

The results that were measured showed no specific trend. All the values that were recorded were in the region of $0.3 \mathrm{~mm}$ deviation. This proved that the dimensional accuracy of the ISC-drill is relatively consistent across all cutting configurations. This can probably be attributed to the small point angle associated with the ISC-drill. It can also be observed that the addition of water had no significant influence on the hole deviation. Figure 10 illustrates the temperatures captured for the HFII-drill plotted as a function of feed and cutting speed while using normal MQL lubricant. 


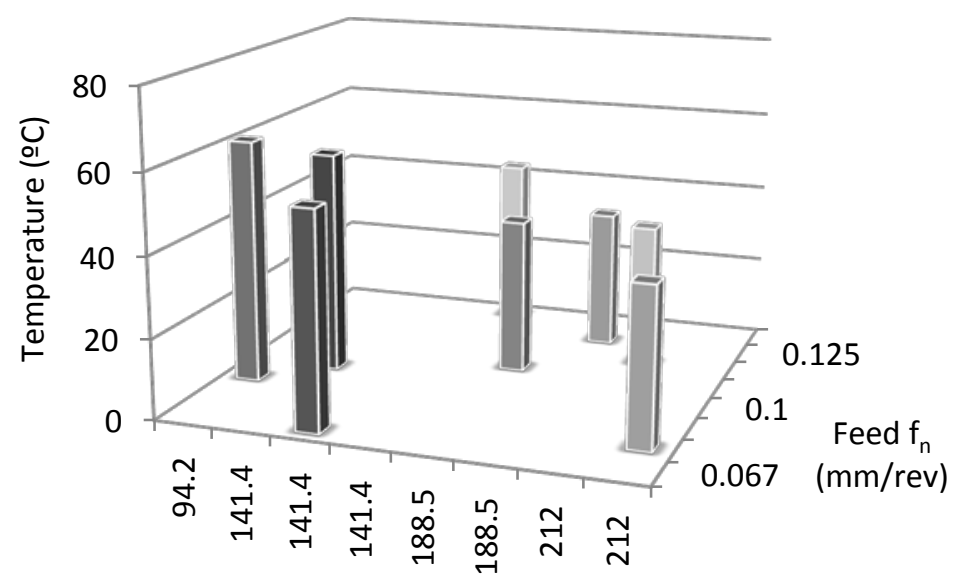

Cutting speed $\mathrm{V}_{\mathrm{c}}(\mathrm{m} / \mathrm{min})$

Figure 10: Post-drilling temperatures for the high feed indexable insert drill

The graph clearly shows a downward trend with an increase in feed and cutting speed. This is completely different from the results for the ISC-drill. The experiments were repeated at the same rotational speeds as for the ISC-drill. The diameter of the high feed indexable insert drill is slightly less than the diameter of the ISC-drill. This meant that a maximum cutting speed of $212 \mathrm{~m} / \mathrm{min}$ and a feed of $0.133 \mathrm{~mm} / \mathrm{rev}$ could be achieved. When the results are compared with those of the ISC-drill, it is evident that lower temperatures were recorded. This could be attributed to the special bevel design of the inserts that assist in the breaking of chips. The lowest temperatures were recorded at cutting speeds of 188.5$212 \mathrm{~m} / \mathrm{min}$ and feeds of $0.11-0.125 \mathrm{~mm} / \mathrm{rev}$. It is expected that the temperatures will rise again at some point if the feed and cutting speed is increased further. The graph is therefore expected to be part of what could be a parabolic function. The maximum cutting speed of the drilling was $212 \mathrm{~m} / \mathrm{min}$. Figure 11 illustrates the hole deviation for the HFIIdrill plotted as a function of feed and cutting speed while using normal MQL lubricant.

The values recorded for the hole-deviation of the HFII-drill with normal MQL lubricant showed that there was a slight decrease in hole deviation with an increase in feed and cutting speed. When compared with the results obtained from the ISC-drill, the HFII-drill proved to be less accurate. This can probably be attributed to the larger point angle and special bevel design of the inserts associated with the HFIl-drill. When drilling, the bevel design can cause the tool to vibrate slightly. This vibration causes the chips in contact with the tool to break more easily. This vibration of the tool could therefore explain the small decrease in dimensional accuracy that was recorded. The most accurate value of about 0.49 $\mathrm{mm}$ hole deviation was recorded at a cutting speed of $212 \mathrm{~m} / \mathrm{min}$ and a feed of 0.11 $\mathrm{mm} / \mathrm{rev}$. The HFIl-drill would therefore be the ideal tool to use for mass production purposes where tight tolerances are not a necessity. Figure 12 illustrates the temperatures recorded for the HFII-drill plotted as a function of feed and cutting speed while using the MQL oil and $21 \%$ water mixture. 


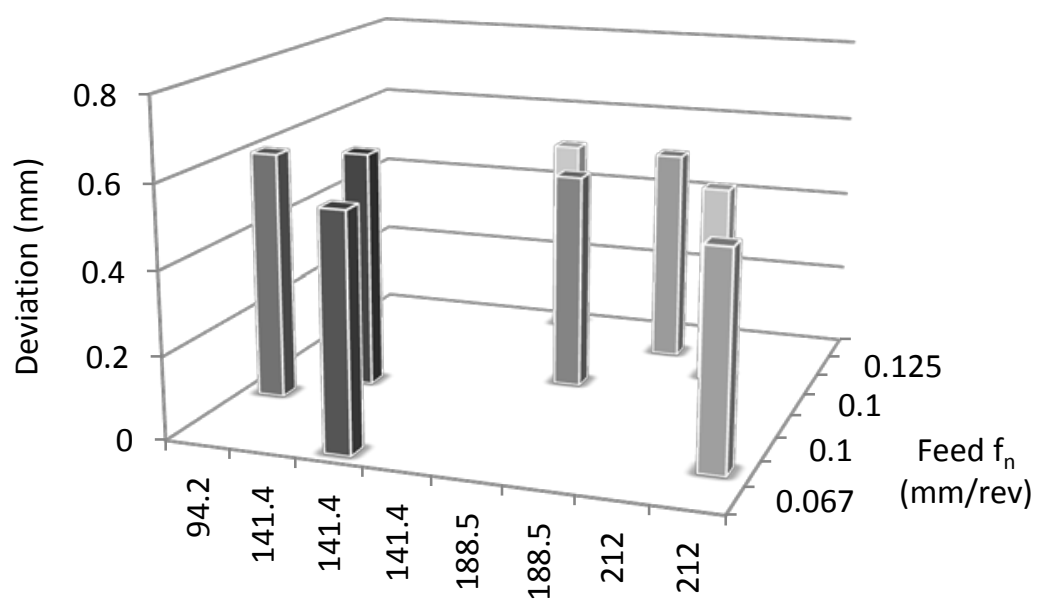

Cutting speed $\mathrm{V}_{\mathrm{c}}(\mathrm{m} / \mathrm{min})$

Figure 11: Hole deviation measurements for the high feed indexable insert drill while using normal MQL lubricant

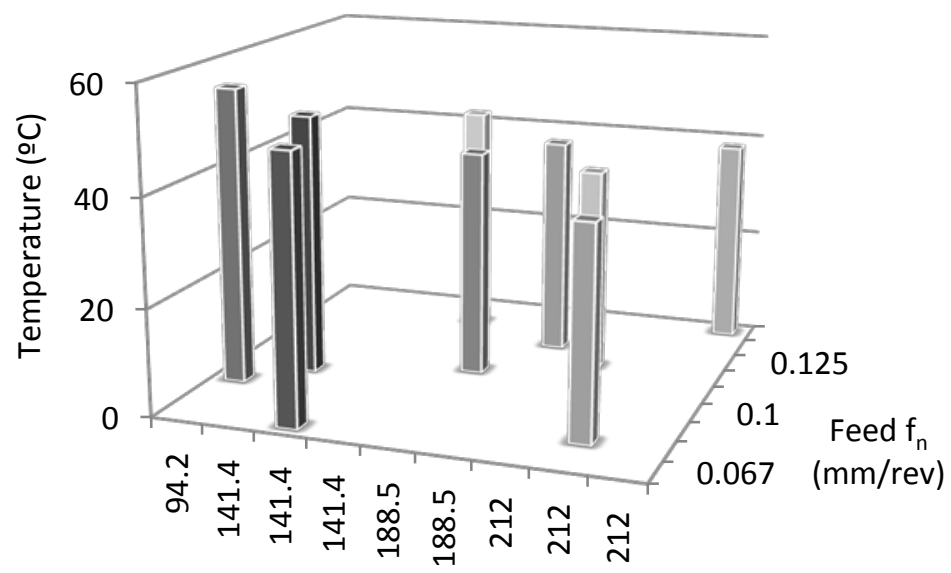

Cutting speed $\mathrm{V}_{\mathrm{c}}(\mathrm{m} / \mathrm{min})$

Figure 12: Post-drilling temperatures for the high feed indexable insert drill with MQL oil and water

As expected, the values recorded for this second series of experiments followed the same trend as for the HFII-drill when normal MQL lubricant was used. With constant feed and increasing cutting speed, a decrease in temperature was recorded. The same was experienced when the cutting speed was held constant and the feed was increased. It is rather interesting to note that all the values that were recorded were less than the values recorded while using normal MQL lubricant. This indicated once more that the addition of water had significantly reduced the heat accumulated during drilling. This is probably due to the higher thermal capacity of the water/ oil mixture. Temperatures were lowest at a cutting speed of $212 \mathrm{~m} / \mathrm{min}$ and feeds of $0.11-0.15 \mathrm{~mm} / \mathrm{rev}$. Figure 13 illustrates the hole deviation measurements for the HFII-drill using MQL and water mixture. 


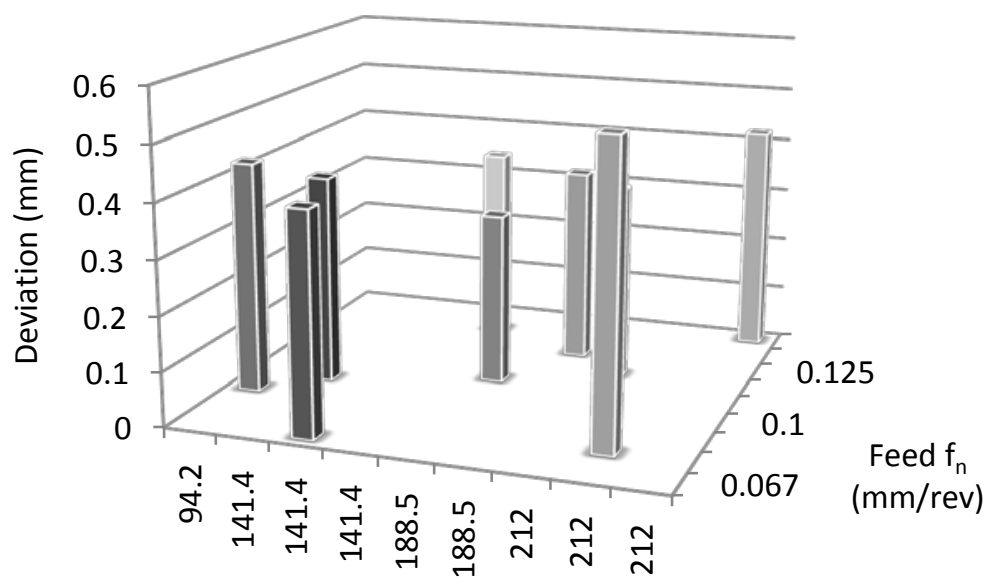

Cutting speed $\mathrm{V}_{\mathrm{c}}(\mathrm{m} / \mathrm{min})$

\section{Figure 13: Hole deviation measurements for the high feed indexable insert drill using the MQL oil and water mixture}

The dimensionally most accurate holes (deviation $=0.32 \mathrm{~mm}$ ) were produced at a cutting speed of $188.5 \mathrm{~m} / \mathrm{min}$ and a feed of $0.1 \mathrm{~mm} / \mathrm{rev}$. Therefore, more accurate holes were produced with the mixture of oil and water than with the MQL oil on its own. This is attributed to the lower temperatures generated with the oil and water mixture, leading to less thermal expansion of the tool, thus producing more accurate holes.

Comparing the environmental impact, conventional flood cooling water-oil emulsion consumption depends largely upon the machine configuration. A disposal volume of 500 litres of water per 10 working days (or 50 litres per day) is taken as the norm for flood cooling. This is compared with 25 millilitres of coolant consumption per hour for MQL, amounting to 200 millilitres per day. This volume of oil is deposited as a film on work pieces, and the $20 \%$ water is lost in evaporation.

\section{CONCLUSION}

From the results recorded in the experiments, the following conclusions were reached:

- MQL methods can be considered a more eco-efficient application for the drilling of aluminium-alloys, as the disposal of approximately 50 litres of potentially harmful water-oil emulsion per day is eliminated.

- The addition of $21 \%$ water had a positive effect on tool wear by reducing the amount of heat generated compared with normal MQL. This resulted in a more energy-efficient lubrication strategy. The lowest temperatures were recorded at a cutting speed of 212 $\mathrm{m} / \mathrm{min}$ and a feed of between $0.11-0.15 \mathrm{~mm} / \mathrm{rev}$.

- Temperatures increased with an increase in feed and cutting speed with the indexable step and chamfer drill. Furthermore, the holes were dimensionally more accurate.

- Temperatures that were recorded for the high feed indexable insert drill followed a different trend than for the indexable step and chamfer drill. Temperatures tended to decrease with an increase in feed and cutting speed. Lower temperatures were also recorded than with the indexable step and chamfer drill, and the hole deviation was also less when water was added to the MQL oil. The reason for this is the lower temperatures generated, causing less tool wear and thermal expansion, leading to less vibration. 


\section{ACKNOWLEDGEMENTS}

Mr Eben du Plessis, Producut (Pty) Ltd, for the supply of MQL lubricant and an indexable step and chamfer drill and the MQL application equipment.

Mr Hein Nel, Sandvik Coromant, for the supply of the high feed indexable insert drill.

Department of Mechanical Engineering, Stellenbosch University for the use of the infrared camera.

Prof Dimitar Dimitrov for being instrumental in securing the funding for the research study.

\section{REFERENCES}

[1] Byrne, G., Dornfeld, D. \& Denkena B. 2003. Advancing cutting technology. Keynote papers STC "C". Annals of CIRP, 52(2), pp 483-508.

[2] Klocke, F. and Arntz, K. 2010. Advancing manufacturing technologies - enablers for efficient products. COMA International Conference on Competitve Manufacturing, Stellenbosch, South Africa, pp 3-6.

[3] Dhar, N.R., Kamruzzaman, M. \& Ahmed, M. 2006. Effect of minimum quantity lubrication (MQL) on tool wear and surface roughness in turning AISI-4340 steel. J ournal of Materials Processing Technology, 172 (2), pp 299-304.

[4] Itoigawa, F., Childs, T., Nakamuraa, T. \& Belluco, W. 2006. Effects and mechanisms in minimal quantity lubrication machining of an aluminum alloy. Wear, 260, pp 339-344.

[5] Bragaa, D., Dinizc, A., Miranda, G. \& Coppini, N. 2002. Using a minimum quantity of lubricant (MQL) and a diamond coated tool in the drilling of aluminum-silicon alloys, J ournal of Materials Processing Technology, 122, 127-138.

[6] Sreejith, P.S. \& Ngoi, B.K.A. 2000. Dry machining: Machining the future. J ournal of Materials Processing Technology, 101 (1), pp 287-291.

[7] Byrne, G. \& Scholta, E. 1993. Environmentally clean machining processes - a strategic approach. Annals of the CIRP, 42 (1), pp 471-474.

[8] Sokovic, M. \& Mijanovic, K. 2001. Ecological aspects of the cutting fluids and its influence on quantifiable parameters of the cutting processes. J ournal of Materials Processing Technology, 109 (1-2), pp 181-189.

[9] Klocke, .F 1997. Dry cutting. Annals of the CIRP, 1997, 46 (2), pp 519-526.

[10] Derflinger, V., Brändle, H. \& Zimmermann, H. 1996. New hard/ lubricant coating for dry machining. J ournal of Surface Coating Technology, 113, pp 286-292.

[11] Neugebauer, R., Blau, P., Harzbecker, C. \& Weilich, D. 2008. Ressourceneffiziente Maschinen- und Prozessgestaltung. CPK 2008: Chemnitzer Produktionstechnisches Kolloquiu, Chemnitz, Germany: Fraunhofer Institut Werkzeugmaschinen und Umformtechnik, pp 49-67.

[12] Sato, M., Ueda, T. \& Tanaka, H. 2007. An experimental technique for the measurement of temperature on CBN tool face in end milling. International J ournal of Machine Tools and Manufacturing, 47 (14), pp 2071-2076.

[13] Ezugwu, E.O. \& Wang, Z.M. 1997. Titanium alloys and their machininability - a review, J ournal of Materials Processing Technology, 68 (3), pp 262-274.

[14] Leskover, P. \& Grum, J. 1986. The metallurgical aspect of machining. Annals of CIRP, 35 (1), pp 537-550.

[15] Tönshoff, H.K. \& Brinksmeier, E. 1986. Determination of the mechanical and thermal influences on machined surface by microhardness and residual stress analysis. Annals of CIRP, 29 (2), pp 519-532.

[16] Su, Y., He, N., Li, L. \& Li, X.L. 2006. An experimental investigation of effects of cooling/lubrication conditions on tool wear in high-speed end milling of Ti-6Al-4V. Wear, 261 (7-8), pp 760-766.

[17] Moufki, A., Molinari, A. \& Dudzinski, D. 1998. Modelling of orthogonal cutting with a temperature dependent friction law. Journal of Mechanics and Physics of Solids, 46, pp 2103-2138. 
[18] Nouari, M., List, G., Girot, F. \& Ge'hin, D. 2005. Effect of machining parameters and coating on wear mechanisms in dry drilling of Al alloys. International J ournal of Machine Tools and Manufacturing, 45 (12-13), pp 1436-1442.

[19] Sandvik Coromant (Pty) Ltd, Sandvik Metalcutting Technical Guide, 2005, E 54. 
http://sajie.journals.ac.za 